\title{
Validation of a rapid, non-radioactive method to quantify internalisation of G-protein coupled receptors
}

\author{
Maikel Jongsma • Urszula M. Florczyk • \\ Mariëlle C. Hendriks-Balk • Martin C. Michel • \\ Stephan L. M. Peters • Astrid E. Alewijnse
}

Received: 8 March 2007 / Accepted: 13 April 2007 / Published online: 12 May 2007

(C) Springer-Verlag 2007

\begin{abstract}
Agonist exposure can cause internalisation of Gprotein coupled receptors (GPCRs), which may be a part of desensitisation but also of cellular signaling. Previous methods to study internalisation have been tedious or only poorly quantitative. Therefore, we have developed and validated a quantitative method using a sphingosine-1-phosphate (S1P) receptor as a model. Because of a lack of suitable binding studies, it has been difficult to study S1P receptor internalisation. Using a N-terminal HisG-tag, $\mathrm{S}^{\mathrm{P}_{1}}$ receptors on the cell membrane can be visualised via immunocytochemistry with a specific anti-HisG antibody. S1P-induced internalisation was concentration dependent and was quantified using a microplate reader, detecting either absorbance, a fluorescent or luminescent signal, depending on the antibodies used. Among those, the fluorescence detection method was the most convenient to use. The relative ease of this method makes it suitable to measure a large number of data points, e.g. to compare the potency and efficacy of receptor ligands.
\end{abstract}

Keywords Sphingosine-1-phosphate receptors · HisG-tag · Quantification · Internalisation · Cellular trafficking ·

G-protein coupled receptor

\section{Introduction}

When chronically exposed to an agonist, G-protein coupled receptors (GPCRs) can undergo desensitisation, i.e. the

M. Jongsma • U. M. Florczyk • M. C. Hendriks-Balk •

M. C. Michel $\cdot$ S. L. M. Peters $\cdot$ A. E. Alewijnse $(\square)$

Department of Pharmacology and Pharmacotherapy,

Academic Medical Center,

Meibergdreef 15,

1105 AZ Amsterdam, The Netherlands

e-mail: A.E.Alewijnse@amc.uva.nl response to a given level of agonist exposure declines, and/ or more agonist is required to maintain the same response. Various mechanisms can be involved in desensitisation, some of which directly affect receptor responsiveness. One of these mechanisms involves phosphorylation of activated receptors by GPCR kinases (GRKs). This enables binding of arrestins to the receptor, leading to uncoupling from the Gprotein and hence impaired signaling. Another, not necessarily mutually exclusive mechanism of desensitisation is internalisation of the receptor, which can be either homologous (because of activation of the receptor) or heterologous (because of activation of other receptors or to other stimuli). Receptor internalisation can be arrestin-dependent or independent (Bünemann and Hosey 1999) and involves translocation of the receptor from the cell membrane to the inside of the cell. There, it is entrapped inside clathrin-coated pits and can undergo either degradation or resensitisation.

Several approaches have been used in the past to detect and quantify GPCR internalisation. One classical method involves homogenisation of tissues or cells, differential centrifugation to yield a plasma membrane and a microsomal fraction followed by electrophoresis and autoradiographical analyses of the receptor of interest in both fractions (Simpson et al. 1984). Another classical method involves labeling of all receptors in intact cells with a lipophilic radioligand and competition by a hydrophilic ligand, which will replace the radioligand from sites at the cell surface but not from those entrapped intracellularly (Staehelin et al. 1983). More recently, genetic approaches have been used. An example is the use of a C-terminal green fluorescent protein (GFP; Barak et al. 1997; Kallal et al. 1998) to monitor receptor localisation after ligand stimulation sometimes combined with an algorithm to discriminate between internalised and membrane-bound receptors (Conway et al. 1999; Fukunaga et al. 2006; Schlag et al. 2004; Hirasawa et al. 2005). This 


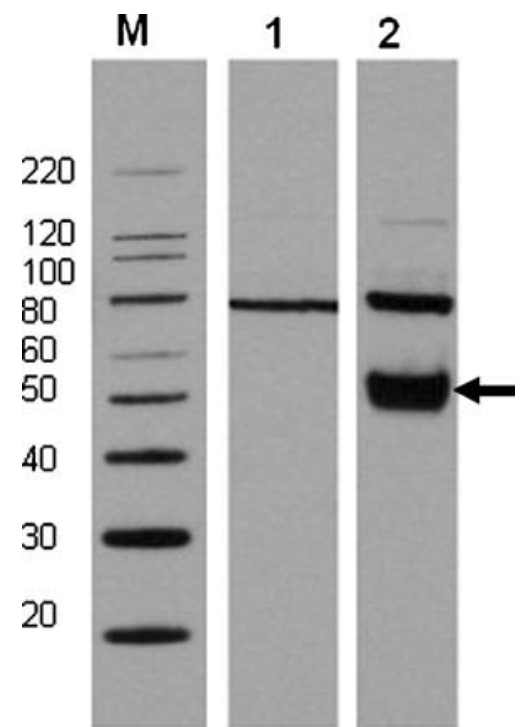

Fig. 1 Western blot of CHO-FlpIn cells stably expressing the $\mathrm{S}_{1} \mathrm{P}_{1}$ receptor (lane 1) and HisG-S1P ${ }_{1}$ receptor (lane 2) using a mouse antiHisG first antibody and a goat anti-mouse HRP second antibody. HisG-S1P $\mathrm{P}_{1}$ is detected at approximately $50 \mathrm{kDa}$ as indicated by the arrow. The band at $80 \mathrm{kDa}$ is nonspecific. The blot shown is from a typical experiment out of four

latter method uses a cell-based fluorescence imaging system ArrayScanII, where the amount of internalised receptor/GFP spots are counted and normalised against the number of nuclei stained with Hoechst 33342. However, a GFP, or other fluorescent tag, is relatively large (200-300 amino acids) and can influence receptor function (McLean and Milligan 2000). Other methods use a combination of techniques, like quantitative flow cytometry analysis of the cell surface receptors and immunocytochemical confocal microscopy analysis to visualise the sub-cellular localisation of the receptor of interest (Hirasawa et al. 1998).

Detailed quantitative studies of internalisation are of interest as this process can be the mechanism of underlying physiological and pharmacological effects. For example, receptor internalisation is thought to underlie the modulation of immune function by sphingosine-1-phosphate (S1P; Matloubian et al. 2004). This also appears to be the mechanism of action of the immunosuppressive drug
FTY720 (fingolimod; Chiba et al. 2006; LaMontagne et al. 2006), which is undergoing clinical trials for the treatment of multiple sclerosis and previously also for renal graft rejection (Budde et al. 2002; Kappos et al. 2006).

In our search to quantify internalisation of membrane receptors in a fast and easy way, we have setup a method, which uses an N-terminal HisG (6xHis+Gly)-tagged S1P receptor. Because the HisG-tag is N-terminal, it is extracellular. Therefore, when immunocytochemistry is performed without permeabilisation, only membrane-bound, tagged receptors will be detected. This way, internalisation is quantified as a difference in membrane-fluorescence between unstimulated and agonist-stimulated cells.

The use of small, N-terminal tags has been described before (Daunt et al. 1997; Vicentic et al. 2002; Wozniak and Limbird 1996; Von Zastrow et al. 1993; Miller 2004). Of these, Daunt et al. 1997 described a method where cells were plated onto 24 well tissue culture dishes. After stimulations with an agonist, incubations with first and second antibodies followed. Measurements were done after adding alkaline phosphatase substrate, resulting in a colorimetric reading. In this paper, we now describe the validation of a similar method by testing various antibody combinations and detection methods to quantify internalisation of N-terminal HisG-tagged receptors. This resulted in immunocytochemical method using a specific anti-HisG first antibody combined with a fluorescent second antibody (AlexaFluor ${ }^{\circledR}$ 488) as our preferred choice. The signal can either be visualised under the fluorescence microscope or measured in a fluorescence microplate reader. The latter results in quantitative measurement of the decrease in signal caused by receptor internalisation, in a direct, sensitive and fast way.

\section{Materials and methods}

\section{Materials}

pcDNA3.1 containing the entire coding region of the human ${\mathrm{S} 1 \mathrm{P}_{1}}_{1}$ receptor was purchased from UMR cDNA Resource Center (Rolla, MO).

Fig. 2 Fluorescence microscope pictures of CHO-FlpIn cells stably expressing the HisG-S1P receptor (a) and the $\mathrm{S}_{1} \mathrm{P}_{1}$ receptor (b) using a mouse antiHisG first antibody and AlexaFluor $^{\circledR} 488$ goat anti-mouse second antibody. Images shown are from one typical experiment out of nine
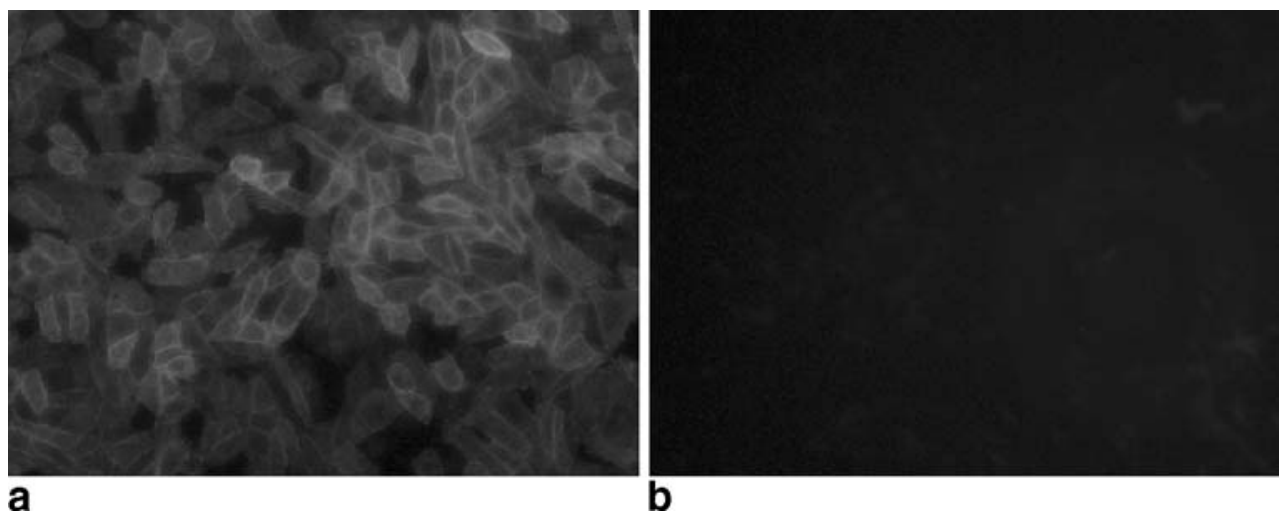
Cell culture media, hygromycine B, Lipofectamine ${ }^{\mathrm{TM}} 2000$, pcDNA3.1/His C, pOG44, CHO-FlpIn cells, Alexa Fluor ${ }^{\circledR}$ 488 goat anti-mouse (IgG), anti-HisG (mouse monoclonal $\mathrm{IgG}_{2 \mathrm{a}}$ ), anti-HisG-horse radish peroxidase (HRP; mouse monoclonal $\mathrm{IgG}_{2 \mathrm{a}}$ ), pcDNA5/FRT/TO, NuPAGE ${ }^{\circledR}$ System, NuPAGE ${ }^{\circledR}$ Novex 4-12\% Bis-Tris gel, MES running buffer, NuPAGE $^{\circledR}$ transfer buffer and Invitrolon ${ }^{\mathrm{TM}}$ PVDF blotting membranes were obtained from Invitrogen (Breda, The Netherlands). BCA ${ }^{\mathrm{TM}}$ Protein Assay Kit was obtained from Pierce (Etten-Leur, The Netherlands). Formaldehyde solution was obtained from Sigma (Zwijndrecht, The Netherlands). Restriction enzymes (BamHI, XhoI, EcoRI and HindIII) were obtained from Fermentas Life Sciences (St. Leon-Rot, Germany). Black, clear bottom 96 well plates were obtained from Greiner Bio One (Alphen aan den Rijn, The Netherlands). S1P was obtained from Avanti-Polar Lipids (via
Instruchemie B.V., Delfzijl, The Netherlands). Chamber slides were obtained from Nunc (Amsterdam, The Netherlands). BM Chemiluminescence Blotting Substrate [POD] and ABTS [2,2'-azino-bis(3-ethylbenzthiazoline-6-sulphonic acid)] were obtained from Roche (Mannheim, Germany). Hyperfilm ECL was obtained from Amersham Biosciences (Diegem, Belgium). SEW2871 (5-(4-Phenyl-5-trifluoromethylthiophen-2-yl)-3-(3-trifluoromethylphenyl)-1,2,4-oxadiazole) was obtained from Calbiochem (via VWR, Amsterdam, The Netherlands). Goat anti-mouse-HRP was obtained from Jackson ImmunoResearch Europe (via Sanbio B.V., Uden, The Netherlands). RIPA buffer was obtained from Boston bio products (Worcester, UK). Halt protease inhibitor cocktail was obtained from Pierce (via Perbio Science Nederland B.V. Etten-Leur, The Netherlands).
Fig. 3 Fluorescence microscope pictures of CHO-FlpIn cells stably expressing the HisG-S1 $\mathrm{P}_{1}$ using a mouse anti-HisG first antibody and AlexaFluor ${ }^{(B)} 488$ goat anti-mouse second antibody. Cells were stimulated for 30 min with $1 \mu \mathrm{M} \mathrm{S} 1 \mathrm{P}$ or $10 \mu \mathrm{M}$ SEW2871 at either $37^{\circ} \mathrm{C}$ (left panel) or $4^{\circ} \mathrm{C}$ (right panel). Images shown are from one typical experiment out of four

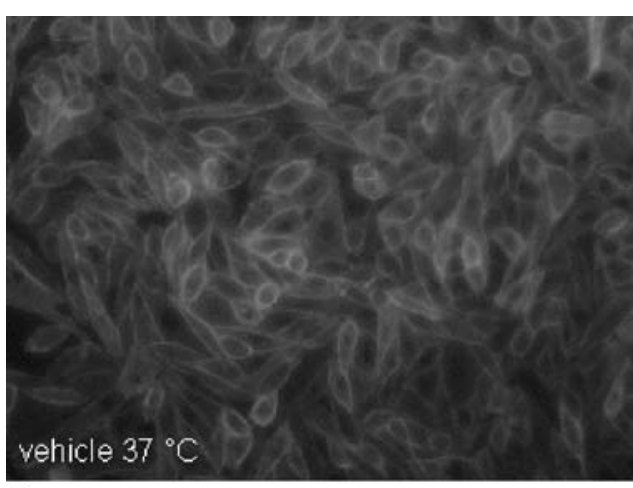

a

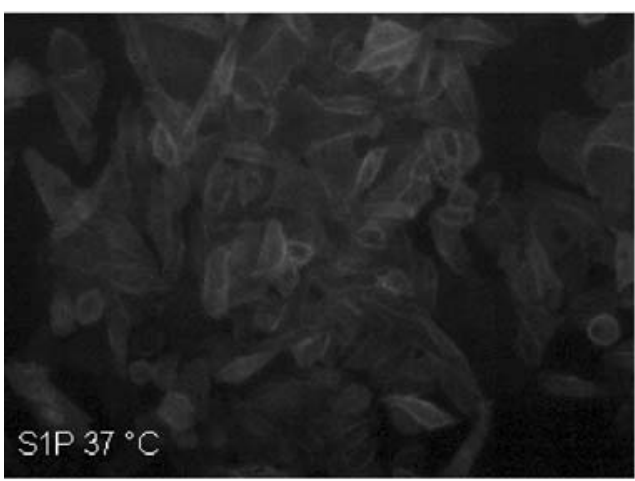

c

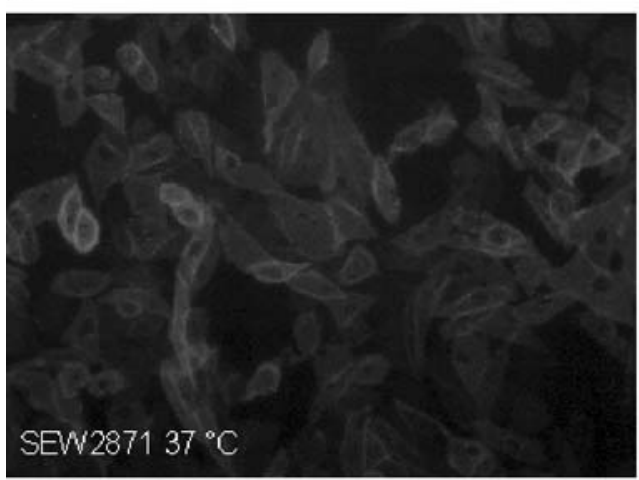

e

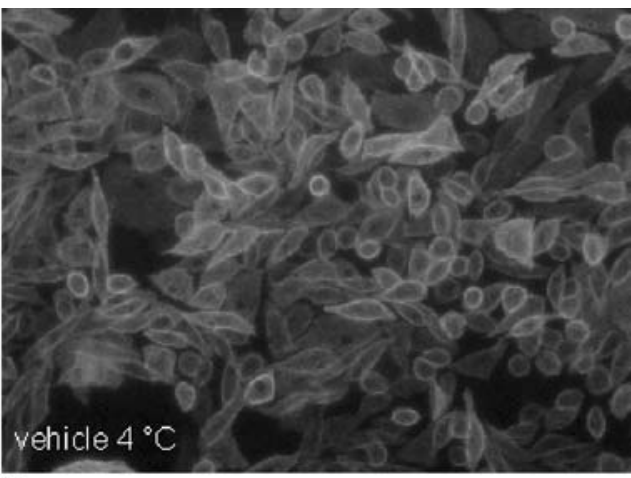

b

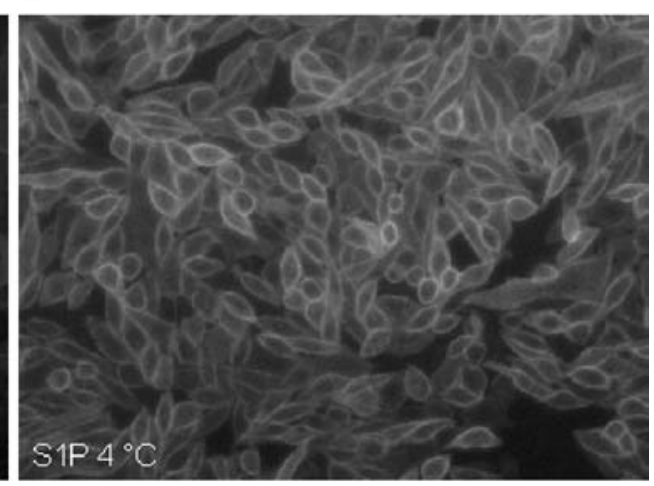

d

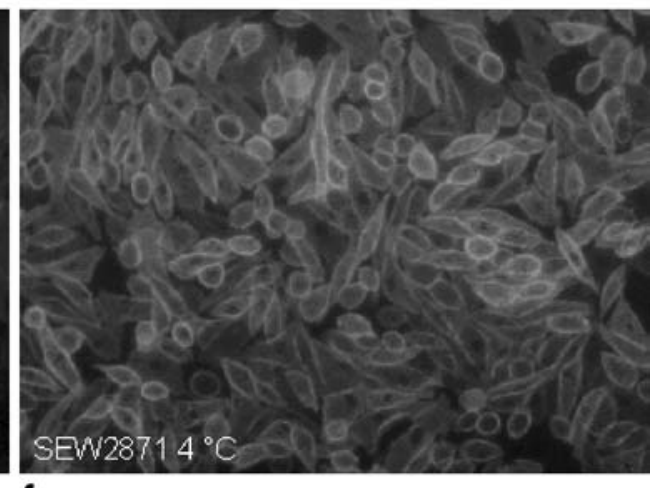


Molecular cloning and transfection

An N-terminal HisG-tag was added to the $\mathrm{S}_{1} \mathrm{P}_{1}$ receptor via cloning into pcDNA3.1/HisC using BamHI and XhoI. A second cloning step was done using HindIII and XhoI to clone the HisG-tagged $\mathrm{S}_{1} \mathrm{P}_{1}$ receptor into the expression vector pcDNA5/FRT/TO. Transfection of plasmids into CHO-FlpIn cells and cell culture was done as described previously (Jongsma et al. 2006).

\section{Western blot}

Cells were washed and scraped in PBS, spun down and lysed in RIPA buffer with protease inhibitor. Protein concentration was determined using the BCA kit according to the manufacturer's protocol. Ten micrograms of protein were loaded onto a $4-12 \%$ NuPAGE ${ }^{\circledR}$ Bis-Tris Gel. Electrophoresis was carried out at $200 \mathrm{~V}$ for $40 \mathrm{~min}$ in $\mathrm{NuPAGE}^{\circledR} \mathrm{MES}$ running buffer. Protein was transferred to Invitrolon ${ }^{\mathrm{TM}}$ PVDF blotting membranes at $30 \mathrm{~V}$ for $1 \mathrm{~h}$. The membrane was blocked for $1 \mathrm{~h}$ at room temperature in $50 \mathrm{mg} / \mathrm{ml} \mathrm{non-fat}$ dry milk in PBS followed by overnight incubation at $4^{\circ} \mathrm{C}$ with a dilution of 1:5,000 for mouse anti-HisG. After washing with PBS-Tween $(0.1 \%)$, the membrane was incubated with a 1:20,000 dilution of goat anti-mouse-HRP IgG at room temperature. Detection was done using BM Chemiluminescence Blotting Substrate and Hyperfilm ECL.

\section{Immunocytochemistry}

Cells $(40,000$ cells/well) were plated on day 1 in 96 wells black, clear bottom plates or eight well chamber slides. The
Fig. 4 Fluorescence microscope pictures of CHO-FlpIn cells stably expressing the HisG-S1P $\mathrm{P}_{1}$ receptor using a mouse antiHisG first antibody and AlexaFluor $^{\circledR} 488$ goat anti-mouse second antibody. Cells were stimulated with S1P at the indicated concentrations at $37^{\circ} \mathrm{C}$ for $30 \mathrm{~min}$. Images shown are from one typical experiment out of four experiments
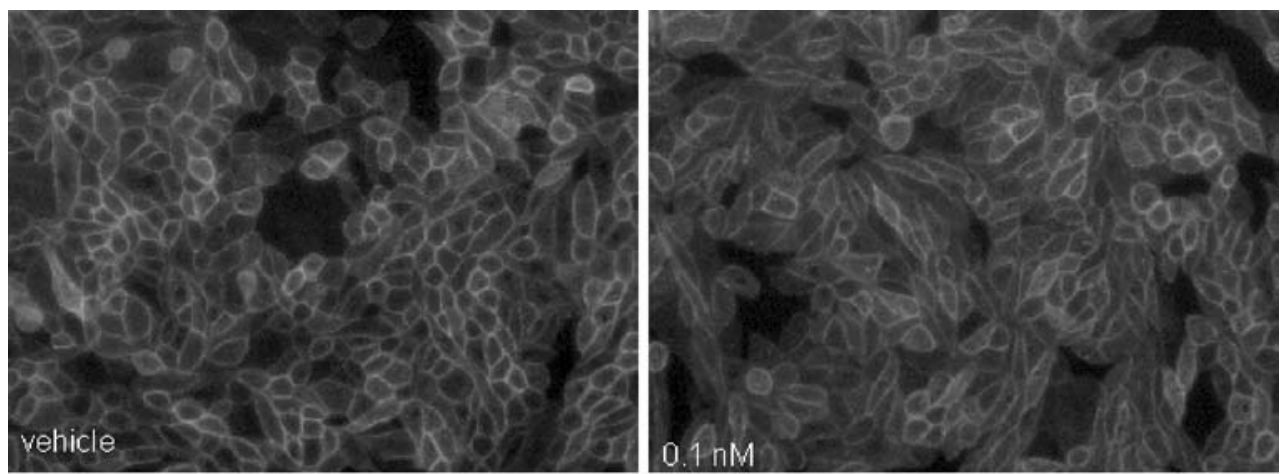

a

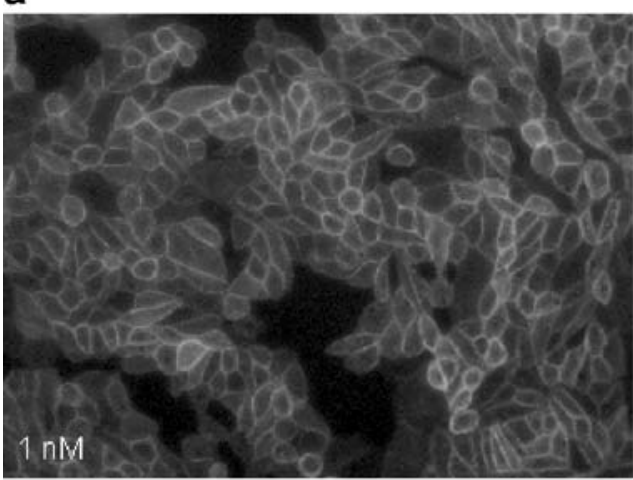

b

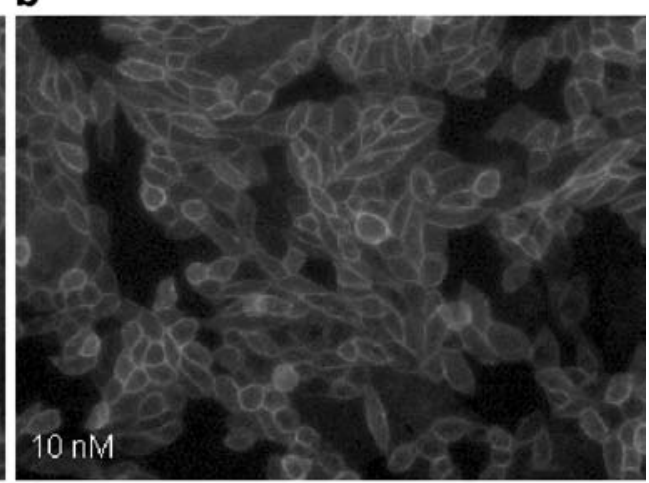

C

d

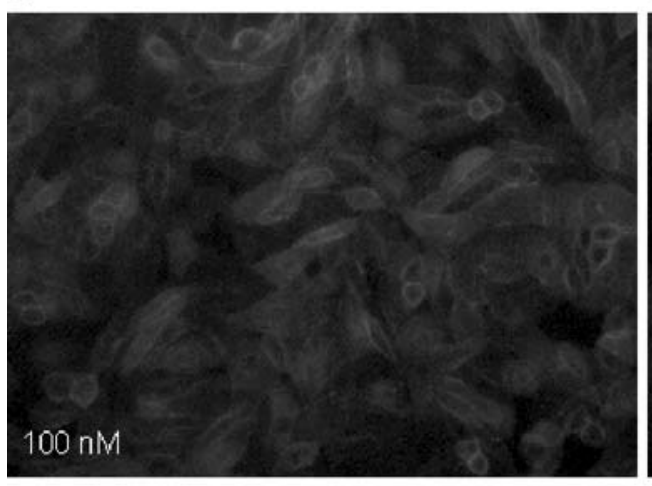

e

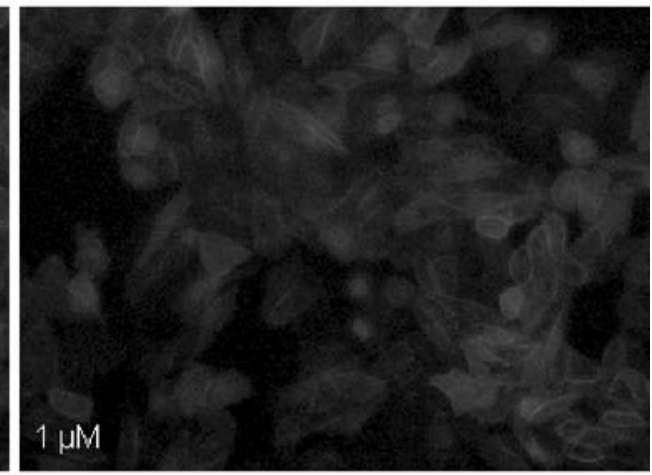

f 
next day, the medium was changed to serum-free medium. After incubation overnight, cells were stimulated with the indicated ligand in serum-free medium for $30 \mathrm{~min}$ at $37^{\circ} \mathrm{C}$, unless otherwise indicated. The stimulation solutions were removed, and cells were fixed by applying $4 \% \mathrm{v} / \mathrm{v}$ formaldehyde in PBS for $15 \mathrm{~min}$ at room temperature. After washing three times with PBS, cells were incubated with the first antibody for $1 \mathrm{~h}$ at room temperature. Cells were washed again three times with PBS and, if necessary, incubated with the second antibody for $1 \mathrm{~h}$ at room temperature. Cells were washed three times with PBS followed by measurements on a Victor2 (Wallac, Perkin Elmer). The following antibody combinations were used: mouse anti-HisG 1:200 with AlexaFluor ${ }^{\circledR} 488$ goat antimouse 1:500, mouse anti-HisG-HRP 1:200 and mouse antiHisG 1:200 with goat anti-mouse-HRP 1:500. In case an HRP-bound antibody was used, either ABTS solution $(50 \mu \mathrm{g} / \mathrm{ml})$ or BM Chemiluminescence Blotting Substrate was added to generate an absorbance or luminescence signal, respectively. For the absorbance signal, a $405-\mathrm{nm}$ filter was used; for the fluorescent signal, a $490-\mathrm{nm}$ excitation and a 535-nm emission filter were used.

\section{Data analysis}

Concentration response curves were analysed by fitting sigmoidal functions to the experimental data using Prism 4 (Graphpad Software, San Diego, CA). Data are expressed as means \pm SEM. Differences between groups were compared using a one way analysis of variance with a Dunnett's correction or a Student's $t$ test where appropriate. $P<0.05$ was considered significant.

\section{Results}

Characterisation of the HisG-tagged $\mathrm{S}_{1} \mathrm{P}_{1}$ receptor

The presence of HisG-S1P ${ }_{1}$ receptor in stably transfected CHO-FlpIn cells was confirmed in Western blot analysis as a band of approximately $50 \mathrm{kDa}$ (Fig. 1). The HisG-S1P receptor was also visualised in the cell membrane by fluorescence microscopy using AlexaFluor ${ }^{\circledR} 488$ goat antimouse as a secondary antibody (Fig. 2). CHO-FlpIn cells stably expressing the untagged $\mathrm{S}_{1} \mathrm{P}_{1}$ receptor were used as a negative control for both detection methods (Figs. 1 and 2). Addition of the N-terminal HisG-tag to the $\mathrm{S}_{1} \mathrm{P}_{1}$ receptor did not influence signaling via this receptor as it did not significantly alter the potency of S1P to inhibit forskolinstimulated cAMP accumulation $\left(\mathrm{pEC}_{50}{\mathrm{~S} 1 \mathrm{P}_{1}} 9.0 \pm 0.1 \mathrm{vs}\right.$ HisG-S1P $18.9 \pm 0.1 ; n=6$ ), measured as described previously (Jongsma et al. 2006).
Internalisation of the $\mathrm{S}_{1} \mathrm{P}_{1}$ receptor

A 30 -min incubation with $1 \mu \mathrm{M}$ of S1P or $10 \mu \mathrm{M}$ of the selective $\mathrm{S}_{1} \mathrm{P}_{1}$ agonist SEW2871 (Sanna et al. 2004) at $37^{\circ} \mathrm{C}$ decreased fluorescence (Fig. 3a, c, e). No such decrease in fluorescence was seen when cells were incubated with either agonist at $4^{\circ} \mathrm{C}$ (Fig. 3b, d, f). S1P concentration dependently internalised the HisG-S1P $\mathrm{P}_{1}$ receptor as visualised with a fluorescence microscope (Fig. 4). Such decrease in fluorescence was also measured using a fluorescence microplate reader. The fluorescent signal of cells stably expressing the HisG-S1P $P_{1}$ receptor was significantly higher than for cells stably expressing the untagged $\mathrm{S}_{1} \mathrm{P}_{1}$ receptor. Stimulation with S1P $(1 \mu \mathrm{M})$ for 30 min significantly decreased this signal (Fig. 5).

\section{Choice of detection method}

Instead of the antibody combination mouse anti-HisG and AlexaFluor $^{\circledR} 488$ goat anti-mouse (Fig. 6a), other combinations were tested to optimise the method. The use of a first antibody mouse anti-HisG-HRP (Fig. 6b) or a first antibody mouse anti-HisG with a second antibody goat anti-mouse-HRP (Fig. 6c) combined with the BM Chemiluminescence Blotting Substrate (POD) resulted in a luminescence signal, which proved to be very sensitive. However, the signal was very unstable over time, which required the addition of the substrate by the microplate reader. The combination of a first antibody mouse anti-

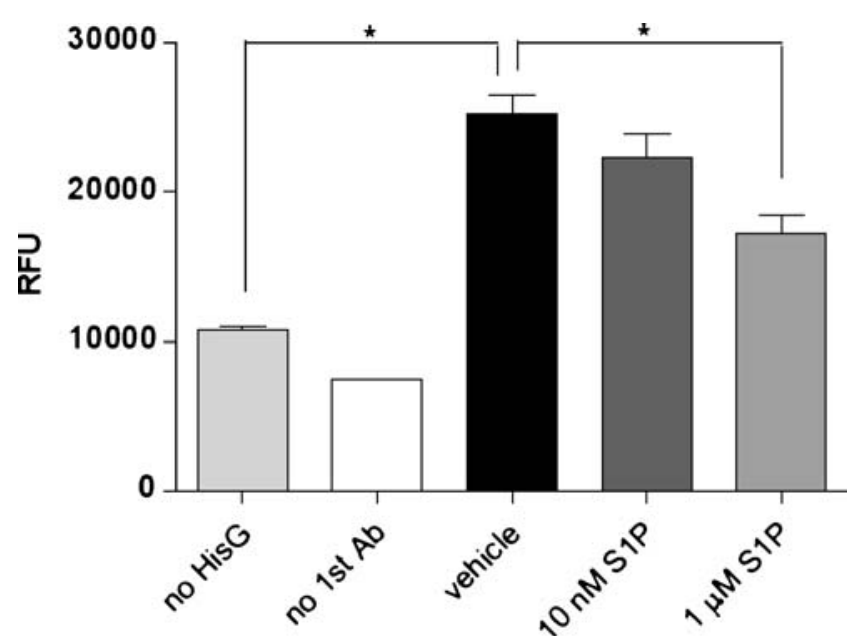

Fig. 5 Quantitative measurements of cells stably expressing HisG$\mathrm{S} \mathrm{P}_{1}$ using a mouse anti-HisG first antibody and AlexaFluor ${ }^{\circledR} 488$ goat anti-mouse second antibody. Cells were stimulated at $37^{\circ} \mathrm{C}$ for $30 \mathrm{~min}$ at the indicated S1P concentrations. The first bar represents cells stably expressing the $\mathrm{S}_{1} \mathrm{P}_{1}$ receptor without a HisG-tag. The second bar represents cells stably expressing HisG-S1 $\mathrm{P}_{1}$ incubated without the first antibody. Statistical significance was shown between 'vehicle' and ' $1 \mu \mathrm{M}$ S1P' as well as between 'no HisG' and 'vehicle'. Data are shown as relative fluorescent units $(\mathrm{RFU}) \pm$ S.E.M. $(n=3)$ 
Fig. 6 Quantitative measurements of HisG-S1P 1 . Ligand stimulations are carried out at $37^{\circ} \mathrm{C}$ for $30 \mathrm{~min}$ at the indicated concentrations $(n=3-4)$. Antibody and detection combinations used are mouse anti-HisG first antibody and AlexaFluor ${ }^{\circledR}$ 488 goat anti-mouse second antibody (a); mouse anti-HisGHRP first antibody+POD (b); mouse anti-HisG first antibody and goat anti-mouse-HRP second antibody+POD (c); mouse anti-HisG-HRP first antibody+ ABTS (d); mouse anti-HisG first antibody and goat antimouse-HRP second antibody+ ABTS (e). Data are shown as percentage of unstimulated $\pm \mathrm{S}$. E.M. An asterisk indicates significant difference compared to unstimulated cells; a pound sign indicates significant difference compared to S1P $(10 \mathrm{nM})$ stimulated cells $1^{\text {st }}$ mouse HisG, $2^{\text {nd }}$ AlexaFluor( 488

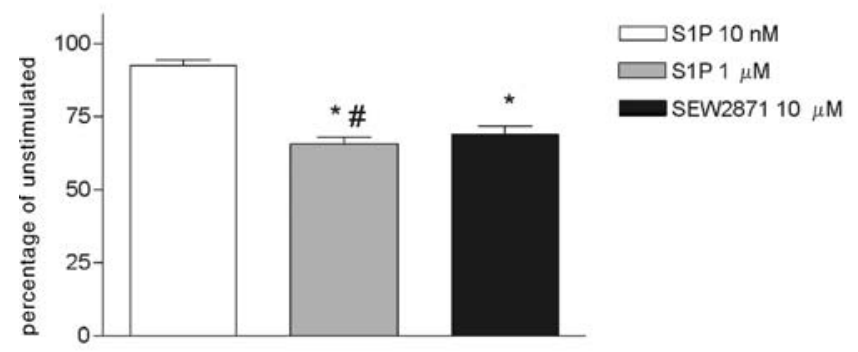

a
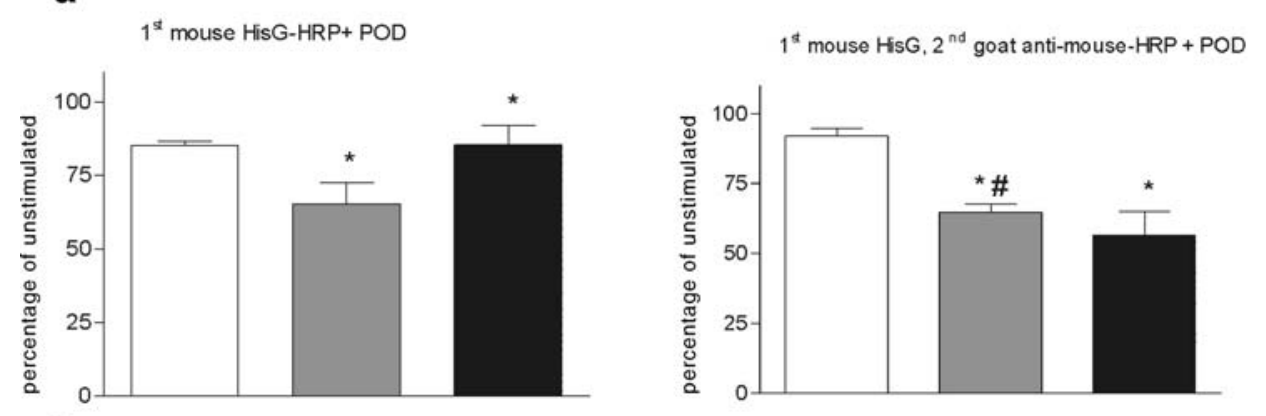

b

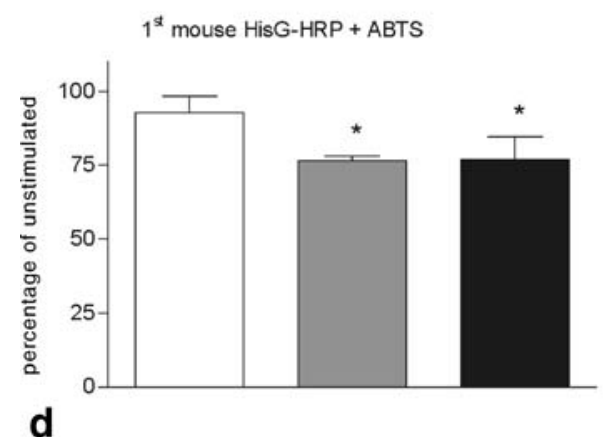

C

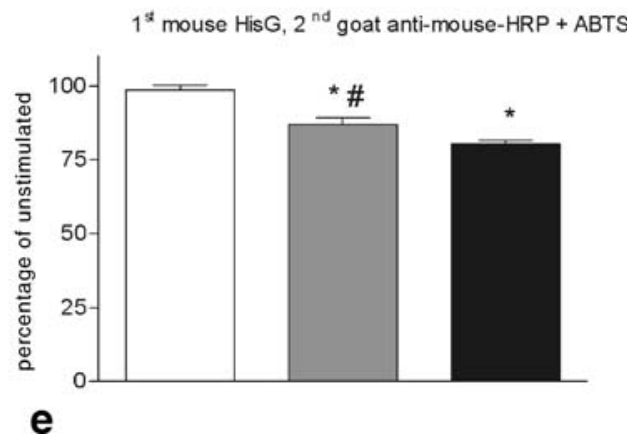

HisG-HRP (Fig. 6d) or a first antibody mouse anti-HisG with a second antibody goat anti-mouse-HRP (Fig. 6e) combined with ABTS resulted in an absorbance signal. This signal however, had less sensitivity compared to the other two detection methods. The use of a first antibody mouse anti-HisG-HRP resulted in a loss of sensitivity compared to the combination of a first antibody mouse antiHisG with a second antibody goat anti-mouse-HRP. When the combination of a first antibody mouse anti-HisG and a second antibody AlexaFluor ${ }^{\circledR} 488$ goat anti-mouse was used, we measured a concentration-dependent internalisation of HisG-S1P 1 after stimulation with either S1P or SEW2871 $\left(\mathrm{pEC}_{50} \mathrm{~S} 1 \mathrm{P}=7.4 \pm 0.1 \quad[n=8]\right.$ and $\mathrm{pEC}_{50}$ SEW2871 $=5.7 \pm 0.2[n=3]$, respectively; Fig. 7).

\section{Discussion}

Previously reported methods to study the internalisation of GPCRs were very labor intensive, required specific equipment, added bulky tags and/or were poorly quanti- tative. We have developed and validated a method that uses stably transfected cells expressing a receptor with a minor modification only, i.e. an N-terminal HisG-tag, which did not influence receptor signaling. Several

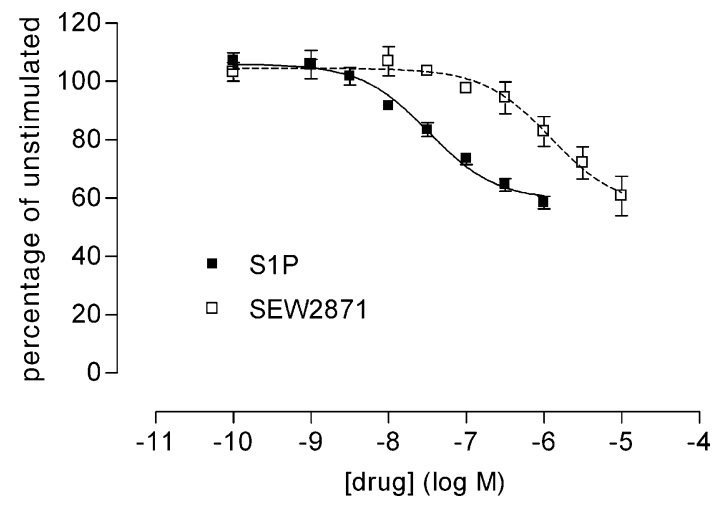

Fig. 7 Effect of increasing concentrations of S1P (closed squares) or SEW2871 (open squares) on CHO-FlpIn cells stably expressing the HisG-S1P ${ }_{1}$ receptor, using a mouse anti-HisG first antibody and AlexaFluor ${ }^{\circledR} 488$ goat anti-mouse second antibody. Stimulations were carried out at $37^{\circ} \mathrm{C}$ for $30 \mathrm{~min}$. The data shown represent the mean $\pm \mathrm{S}$. E.M. of six independent experiments performed in triplicate 
antibody combinations and detection methods were tested. The luminescent approach was very sensitive but highly dependent on strict adherence to a specific time interval between substrate addition and actual signal measurement. The absorbent signal obtained using another detection substrate resulted in a loss of sensitivity. The antibody combination of a first HisG specific antibody and a second AlexaFluor ${ }^{\circledR} 488$ fluorescent antibody proved the most convenient, resulting in a sensitive and stable signal. Compared to previously published methods using a similar approach (Daunt et al. 1997; Vicentic et al. 2002; Wozniak and Limbird 1996; Von Zastrow et al. 1993), this immunocytochemical detection of the N-terminal HisG-tag is suitable to assess a large number of samples, e.g. to construct detailed concentration response curves and/or compare multiple ligands. In this regard, we showed that S1P was approximately 50 times more potent than SEW2871 in internalising the HisG-S1 $\mathrm{P}_{1}$ receptor. This is in good agreement with the previously reported potency difference between the two agonists for activating the receptor (Sanna et al. 2004). As comparable methods have been described for adrenergic receptors as mentioned above (Daunt et al. 1997; Vicentic et al. 2002; Wozniak and Limbird 1996; Von Zastrow et al. 1993), it is likely that the method we described here is also suitable for receptors other than our model receptor, $\mathrm{S}_{1} \mathrm{P}_{1}$.

While our technique does not allow following internalisation in real time, the ability to process a large number of samples compensates for that by studying multiple time points. The only limitation to our method is the inability to measure internalisation of endogenous receptors. However, this would be possible when specific receptor antibodies are available, which is not yet the case for our model receptor.

In conclusion, we have validated a method to quantitatively measure receptor internalisation in which we use an N-terminal HisG-tag combined with immunocytochemistry. It proves to be sensitive enough to discriminate between different receptor ligands in a fast and nonradioactive way.

\section{References}

Barak LS, Ferguson SSG, Zhang J, Martenson C, Meyer T, Caron MG (1997) Internal trafficking and surface mobility of a functionally intact $\beta_{2}$-adrenergic receptor-green fluorescent protein conjugate. Mol Pharmacol 51:177-184

Budde K, Schmouder RL, Brunkhorst R, Nashan B, Lucker PW, Mayer T, Choudhury S, Skerjanec A, Kraus G, Neumayer HH (2002) First human trial of FTY720, a novel immunomodulator, in stable renal transplant patients. J Am Soc Nephrol 13:10731083

Bünemann M, Hosey MM (1999) G-protein coupled receptor kinases as modulators of G-protein signaling. J Physiol 517:5-23
Chiba K, Matsuyuki H, Maeda Y, Sugahara K (2006) Role of sphingosine 1-phosphate receptor type 1 in lymphocyte egress from secondary lymphoid tissues and thymus. Cell Mol Immunol 3:11-19

Conway BR, Minor LK, Xu JZ, Gunnet JW, DeBiasio R, D'Andrea MR, Rubin R, DeBiasio R, Giuliano K, DeBiasio L, Demarest KT (1999) Quantification of G-protein coupled receptor internalisation using G-protein coupled receptor-green fluorescent protein conjugates with the ArrayScantrade mark high-content screening system. J Biomol Screen 4:75-86

Daunt DA, Hurt C, Hein L, Kallio J, Feng F, Kobilka BK (1997) Subtype-specific intracellular trafficking of $\alpha_{2}$-adrenergic receptors. Mol Pharmacol 51:711-720

Fukunaga S, Setoguchi S, Hirasawa A, Tsujimoto G (2006) Monitoring ligand-mediated internalization of $\mathrm{G}$ protein-coupled receptor as a novel pharmacological approach. Life Sci $80: 17-23$

Hirasawa A, Awaji T, Sugawara T, Tsujimoto A, Tsujimoto G (1998) Differential mechanism for the cell surface sorting and agonistpromoted internalisation of the $\alpha_{1 \mathrm{~B}}$-adrenoceptor. $\mathrm{Br} \mathrm{J}$ Pharmacol 124:55-62

Hirasawa A, Tsumaya K, Awaji T, Katsuma S, Adachi T, Yamada M, Sugimoto Y, Miyazaki S, Tsujimoto G (2005) Free fatty acids regulate gut incretin glucagon-like peptide-1 secretion through GPR120. Nat Med 11:90-94

Jongsma M, Hendriks-Balk MC, Michel MC, Peters SLM, Alewijnse AE (2006) BML-241 fails to display selective antagonism at the sphingosine-1-phosphate receptor, $\mathrm{S}_{1} \mathrm{P}_{3} . \mathrm{Br} \mathrm{J}$ Pharmacol 149:277-282

Kallal L, Gagnon AW, Penn RB, Benovic JL (1998) Visualization of agonist-induced sequestration and down-regulation of a green fluorescent protein-tagged $\beta_{2}$-adrenergic receptor. J Biol Chem 273:322-328

Kappos L, Antel J, Comi G, Montalban X, O'Connor P, Polman CH, Haas T, Korn AA, Karlsson G, Radue EW (2006) Oral fingolimod (FTY720) for relapsing multiple sclerosis. N Engl J Med 355:1124-1140

LaMontagne K, Littlewood-Evans A, Schnell C, O'Reilly T, Wyder L, Sanchez T, Probst B, Butler J, Wood A, Liau G, Billy E, Theuer A, Hla T, Wood J (2006) Antagonism of sphingosine-1phosphate receptors by FTY720 inhibits angiogenesis and tumor vascularization. Cancer Res 66:221-231

Matloubian M, Lo CG, Cinamon G, Lesneski MJ, Xu Y, Brinkmann V, Allende ML, Proia RL, Cyster JG (2004) Lymphocyte egress from thymus and peripheral lymphoid organs is dependent on S1P receptor 1. Nature 427:355-360

McLean AJ, Milligan G (2000) Ligand regulation of green fluorescent protein-tagged forms of the human $\beta_{1}$-and $\beta_{2}$-adrenoceptors: comparisons with the unmodified receptors. Br J Pharmacol 130:1825-1832

Miller JW (2004) Tracking G protein-coupled receptor trafficking using Odyssey imaging. Published August by LI-COR Biosciences (http://www.licor.com/bio/PDF/Miller_GPCR.pdf accession date Jan 12 2007)

Sanna MG, Liao J, Jo E, Alfonso C, Ahn MY, Peterson MS, Webb B, Lefebvre S, Chun J, Gray N, Rosen H (2004) Sphingosine 1phosphate $(\mathrm{S} 1 \mathrm{P})$ receptor subtypes $\mathrm{S}_{1} \mathrm{P}_{1}$ and $\mathrm{S}_{1} \mathrm{P}_{3}$, respectively, regulate lymphocyte recirculation and heart rate. J Biol Chem 279:13839-13848

Schlag BD, Lou Z, Fennell M, Dunlop J (2004) Ligand dependency of 5-hydroxytryptamine $2 \mathrm{C}$ receptor internalization. J Pharmacol Exp Ther 310:865-870

Simpson IA, Hedo JA, Cushman SW (1984) Insulin-induced internalisation of the insulin receptor in the isolated rat adipose cell. Detection of both major receptor subunits following their biosynthetic labeling in culture. Diabetes 33:13-18 
Staehelin M, Simons P, Jaeggi K, Wigger N (1983) CGP-12177: a hydrophilic beta-adrenergic receptor radioligand reveals high affinity binding of agonists to intact cells. J Biol Chem 258:3496-3502

Vicentic A, Robeva A, Rogge G, Uberti M, Minneman KP (2002) Biochemistry and pharmacology of epitope-tagged $\alpha_{1}$-adrenergic receptor subtypes. J Pharmacol Exp Ther 302:58-65
Wozniak M, Limbird LE (1996) The three $\alpha_{2}$-adrenergic receptor subtypes achieve basolateral localization in Madin-Darby canina kidney II cells via different targeting mechanisms. J Biol Chem 271:5017-5024

Von Zastrow M, Link R, Daunt D, Barsch G, Kobilka B (1993) Subtype-specific differences in the intracellular sorting of $G$ protein-coupled receptors. J Biol Chem 268:763-766 